\title{
Study of Lean NOx Technology for Diesel Emission Control
}

\author{
R. Mital*, S. C. Huang and B. J. Stroia \\ Cummins Engine Co. \\ And \\ C. Z. Wan
}

Engelhard Corporation

$6^{\text {th }}$ Diesel Engine Exhaust Reduction Workshop

August 21, 2000 


\section{Presentation Outline}

$\bullet$

Introduction

Test Setup

Analysis Tool

Reactor Test Results

Engine Test Results

Analysis Results

Conclusions 


\section{Introduction}

1. Diesel engines because of their reliability and efficiency are a popular mobile source.

2. The diesel engine operates at higher compression ratios and with leaner fuel mixtures and produces lower carbon monoxide and hydrocarbon emissions.

3. The oxygen-rich environment leads to higher nitrogen oxides in the form of NO.

4. Catalysts selectively promoting the reduction of NOx by HCs in a lean environment have been termed lean NOx catalyst "LNC".

5. The two groups that have shown most promise are, Copper exchanged zeolite $\mathrm{Cu} / \mathrm{ZSM} 5$, and Platinum on alumina $\mathrm{Pt} / \mathrm{Al}_{2} \mathrm{O}_{3}$. 


\section{Experimental Setup}

1. Engelhard catalyst was tested in the present work.

2. Testing was done using a Cummins ISB engine.

3. Gas sampling and temperature measurements were made at turbo-out, catalyst-in and catalyst-out locations.

4. Both single and dual brick combinations were tested.

5. Various speeds and loads were tested, rpm varying from 1200

to 2800 and torque varying from 50 to $300 \mathrm{lb}$.- $\mathrm{ft}$. Carbon to

Nitrogen $(\mathrm{CN})$ ratio was varied from 1 to 10. 


\section{Analysis Tool}

The objective was to develop an analysis tool which can assist in understanding the relative importance of various parameters in Lean NOx and facilitate design of critical experiments to evaluate lean NOx technology.

The Lean NOx mechanism may be represented by two reactions, the oxidation of the hydrocarbon and the reduction of nitric oxide:

$\mathrm{C}_{\mathrm{x}} \mathrm{H}_{\mathrm{y}}+(\mathrm{x}+\mathrm{y} / 4) \mathrm{O}_{2} \rightarrow \mathrm{xCO}_{2}+(\mathrm{y} / 2) \mathrm{H}_{2} \mathrm{O}$

$\mathrm{NO}+\mathrm{C}_{\mathrm{x}} \mathrm{H}_{\mathrm{y}}+(\mathrm{x}+\mathrm{y} / 4-1 / 2) \mathrm{O}_{2} \rightarrow \mathrm{xCO}_{2}+(\mathrm{y} / 2) \mathrm{H}_{2} \mathrm{O}+1 / 2 \mathrm{~N}_{2}$ 


\section{Assumptions}

1. The rectangular passages of the monolith have been reduced to a single, cylindrical, isothermal passage.

2. The walls of the passage are assumed isothermal so that only the convective transport and transverse diffusion of species are considered.

3. Flow in the passage is assumed to be fully developed throughout.

4. Surface reactions are assumed to be adequately describes by overall rates given by global kinetic rate laws. 
Effect of cell density (cells per square inch) on NOx conversion

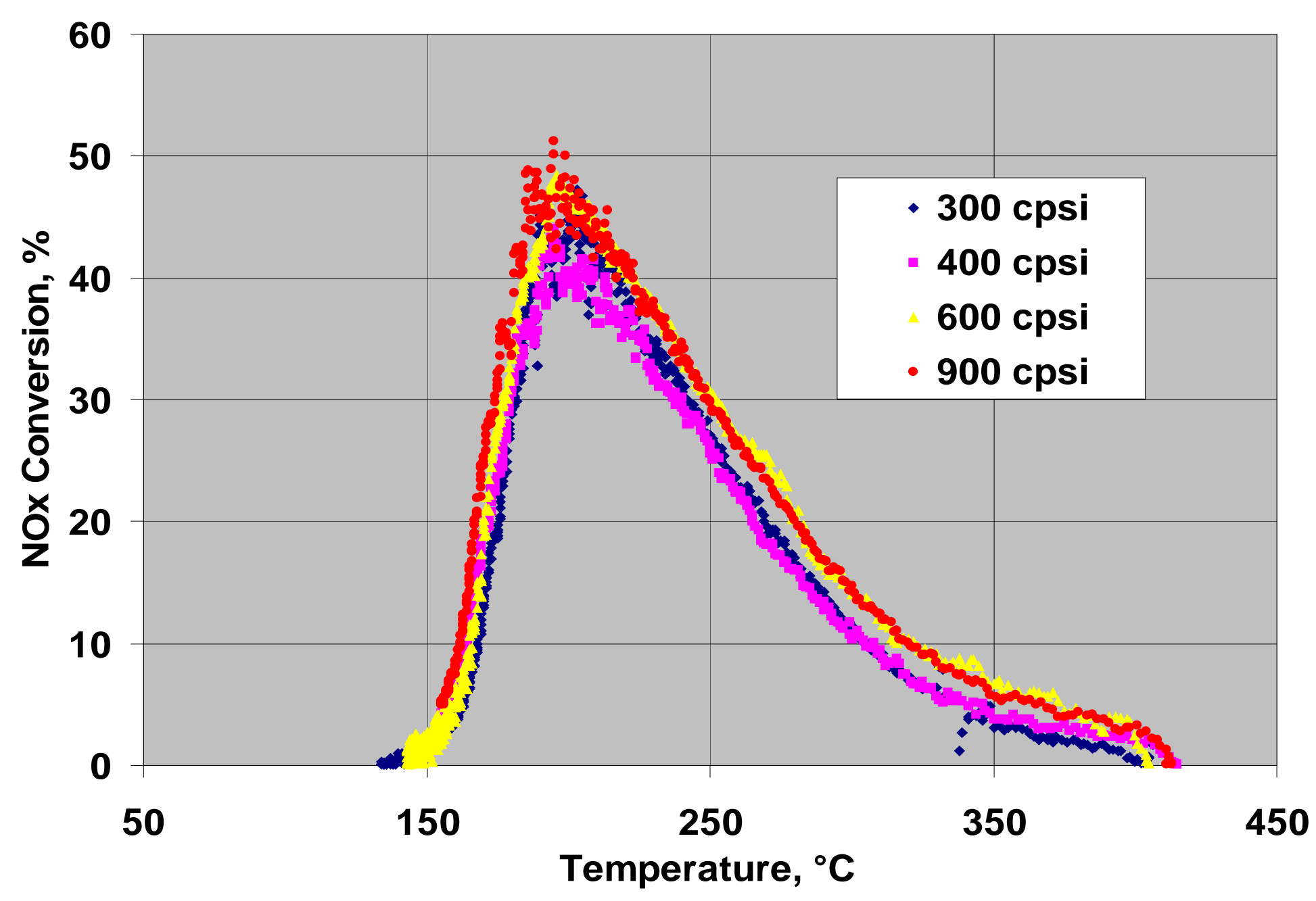




\section{Effect of Pt loading on NOx conversion}

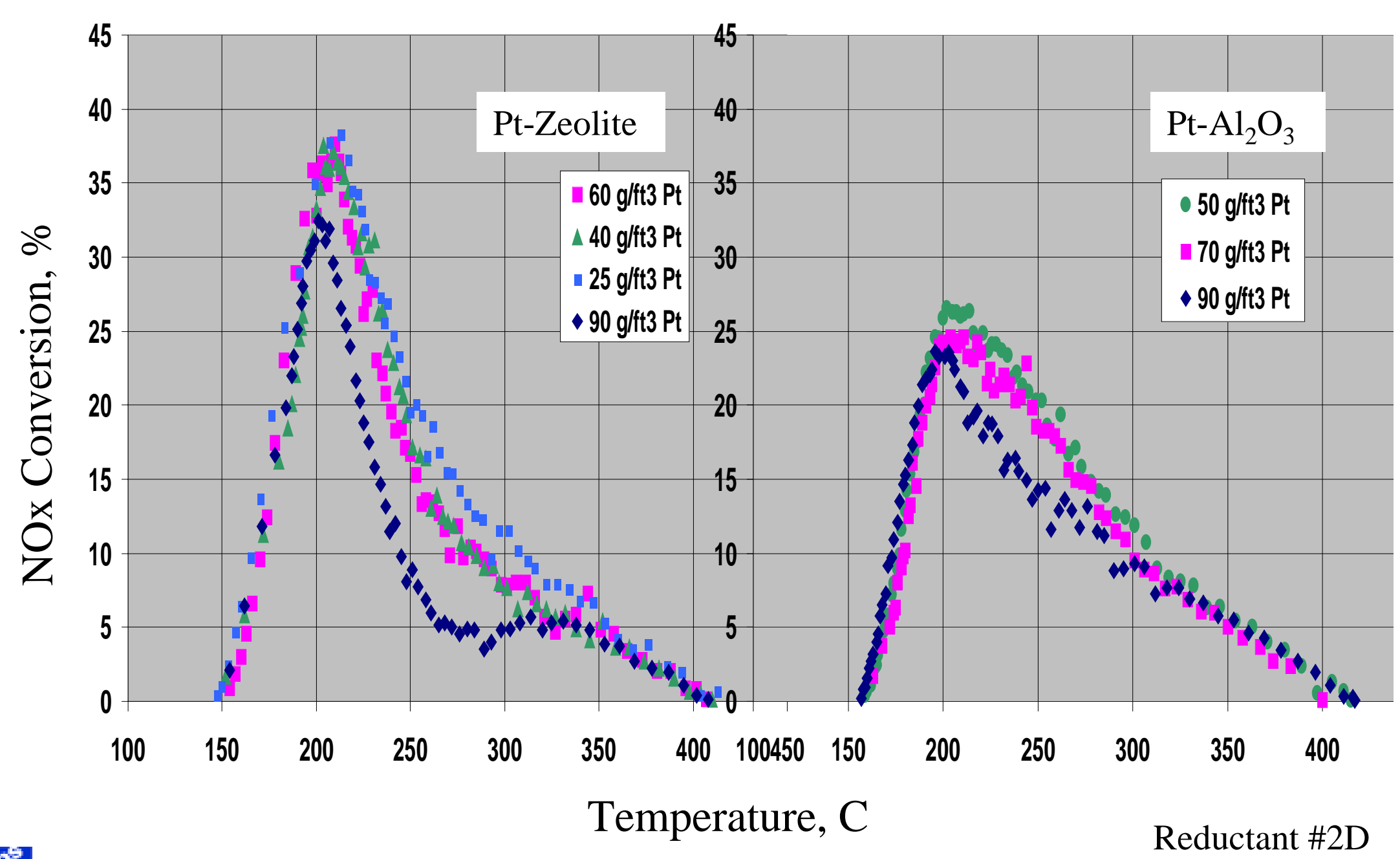

DEER 


\section{Engine Test Results}

\section{Effect of Injector Location on NOx Conversion}

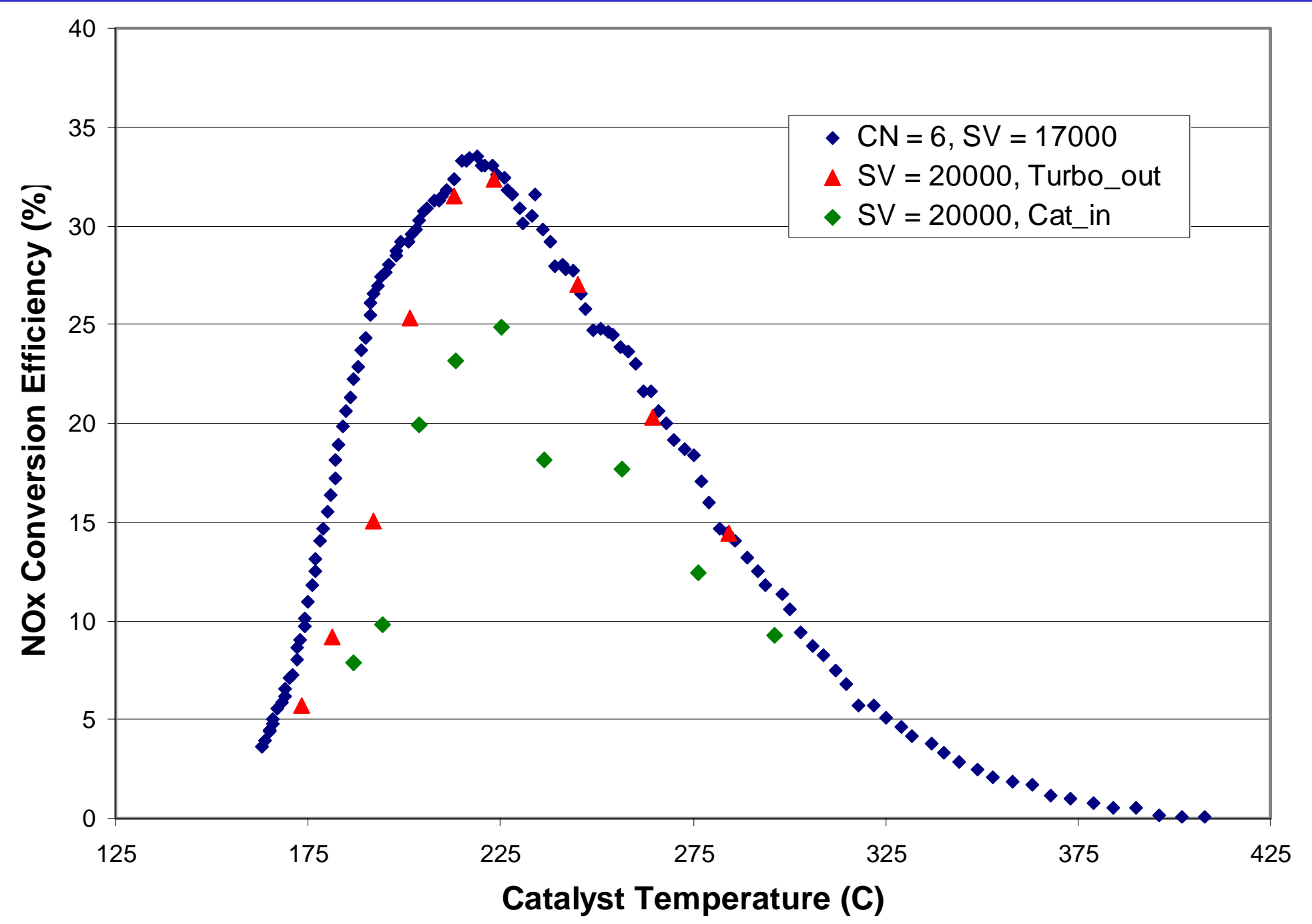

DEER

$8 / 21 / 00$ 


\section{Engine Test Results}

Effect of reductant on NOx conversion efficiency

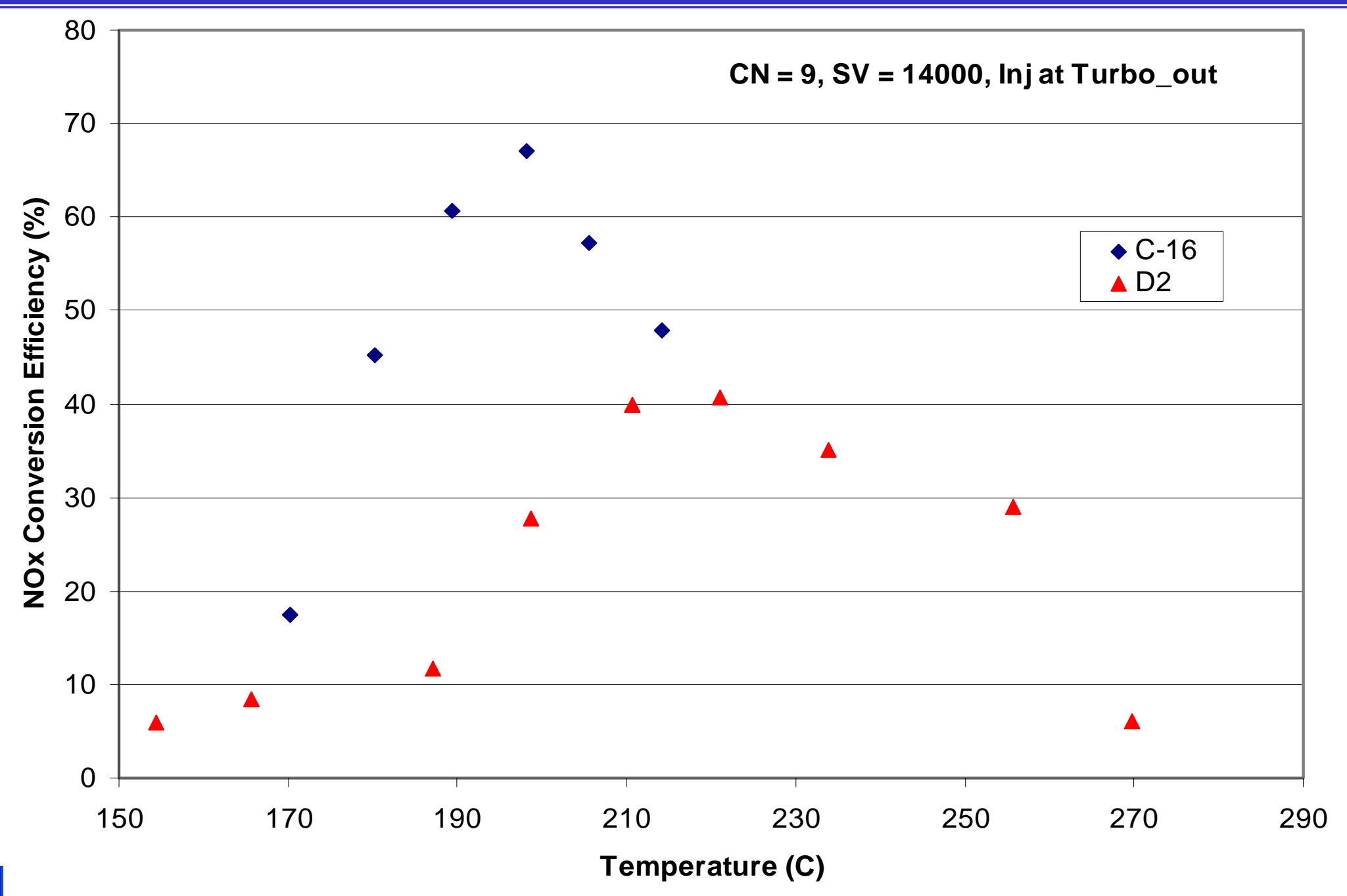

DEER $8 / 21 / 00$ 


\section{Engine Test Results}

\section{Effect of catalyst size on NOx conversion efficiency}

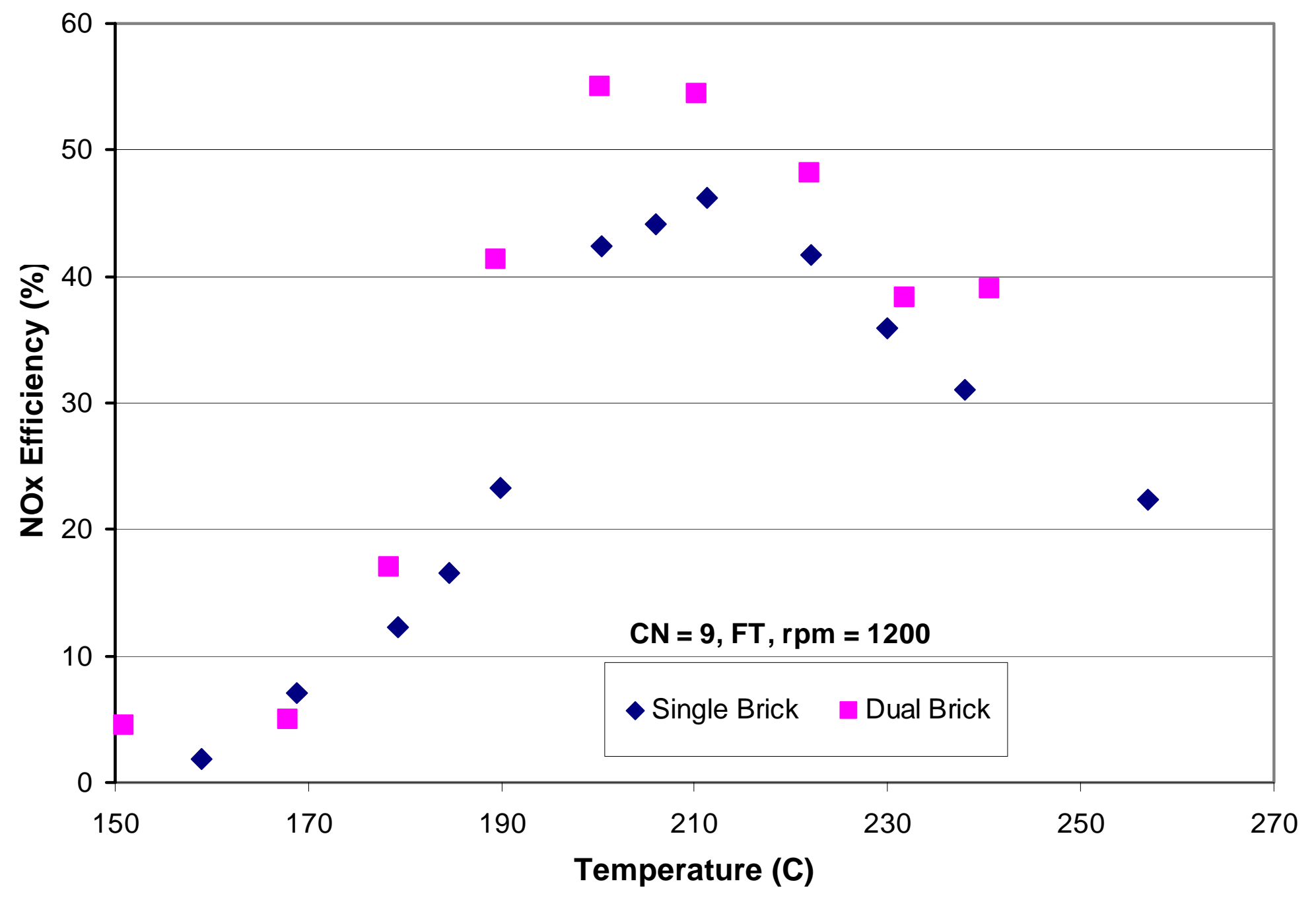

DEER

$8 / 21 / 00$ 


\section{Engine Test Results}

\section{Effect of catalyst size on NOx conversion efficiency}

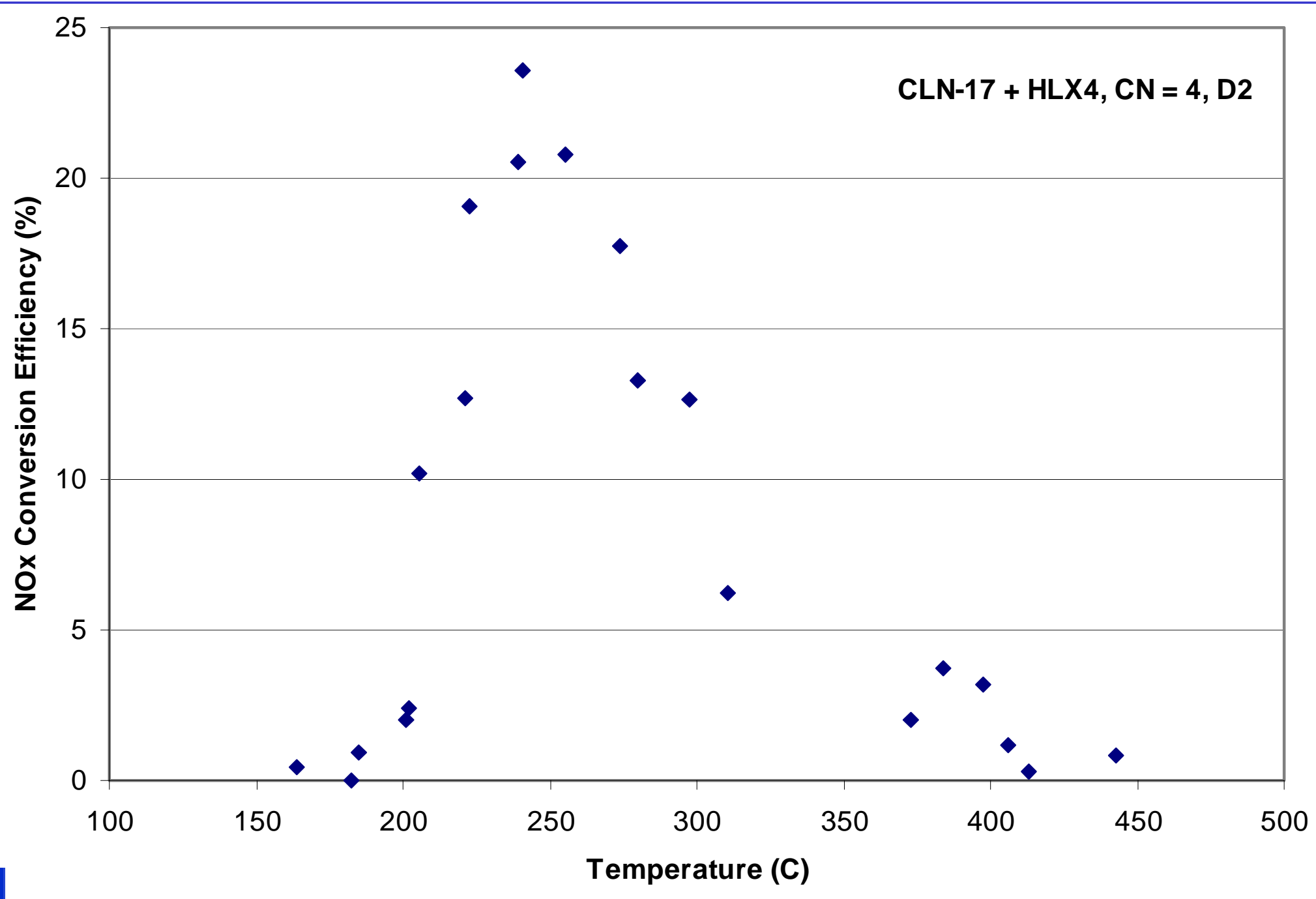

DEER

$8 / 21 / 00$ 


\section{Engine Test Results}

\section{Effect of catalyst size on NOx conversion efficiency}

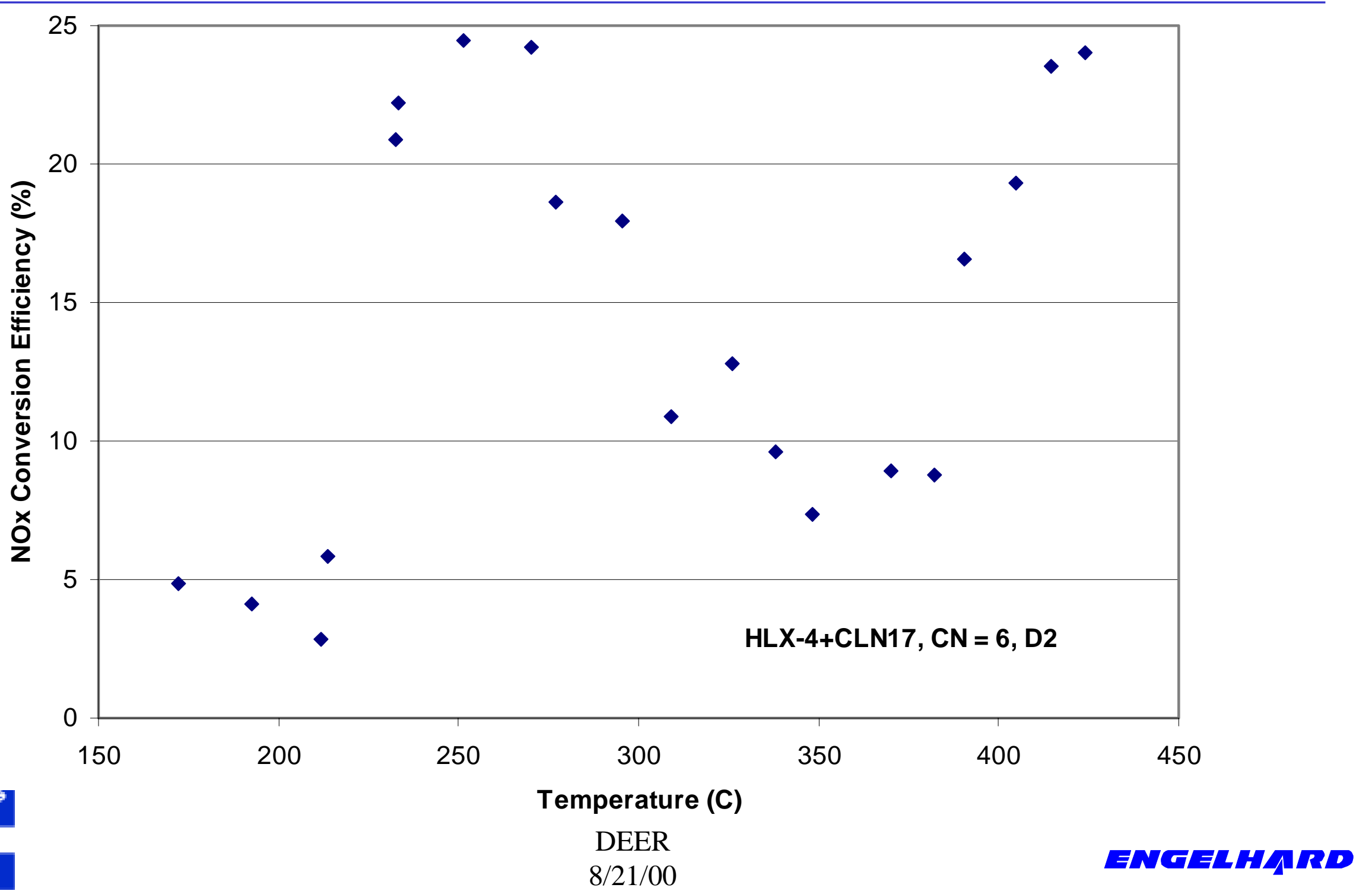




\section{Analysis Results}
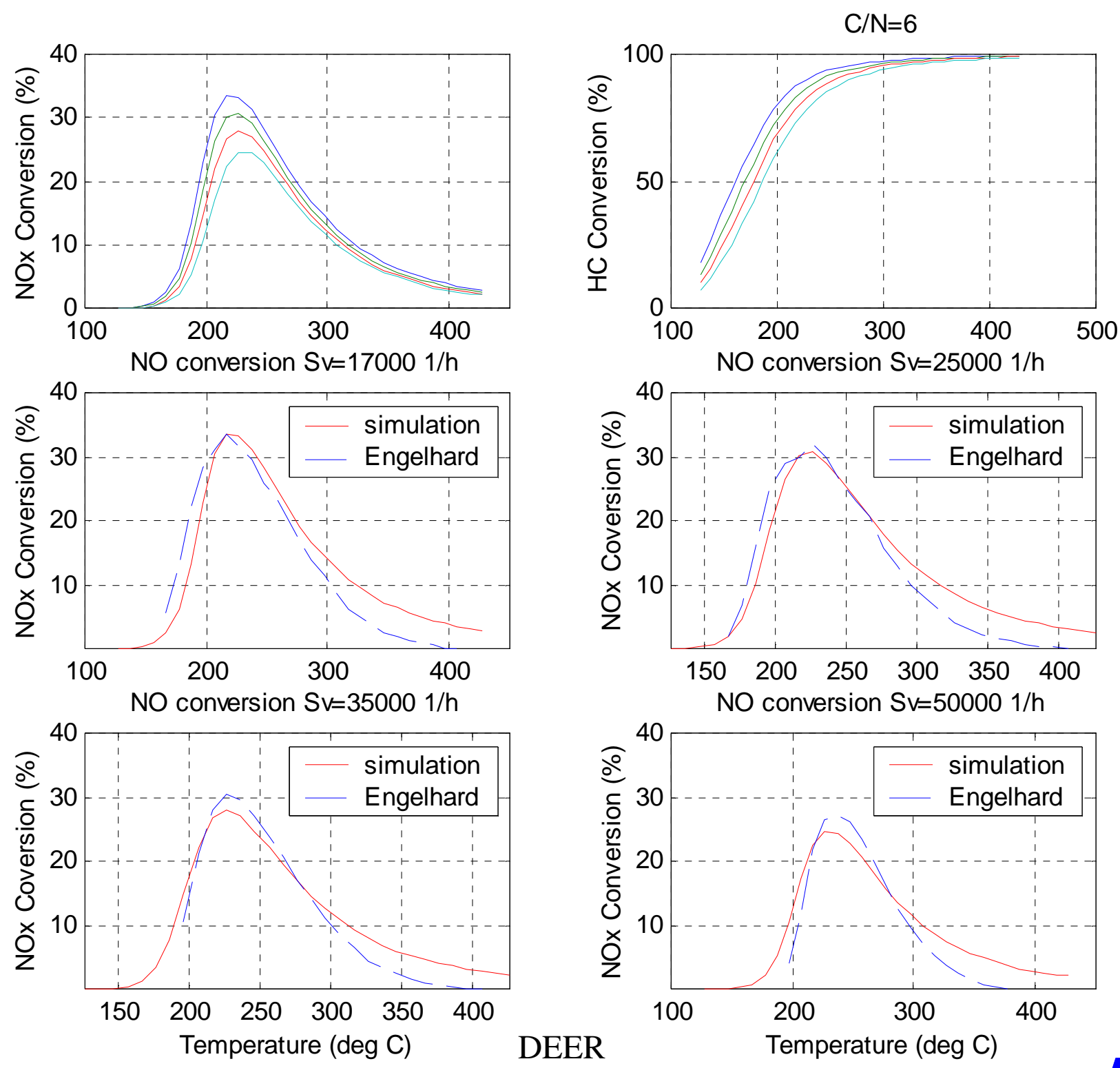


\section{Analysis Results}

Effect of Oxygen in the Exhaust on NOx Conversion Efficiency

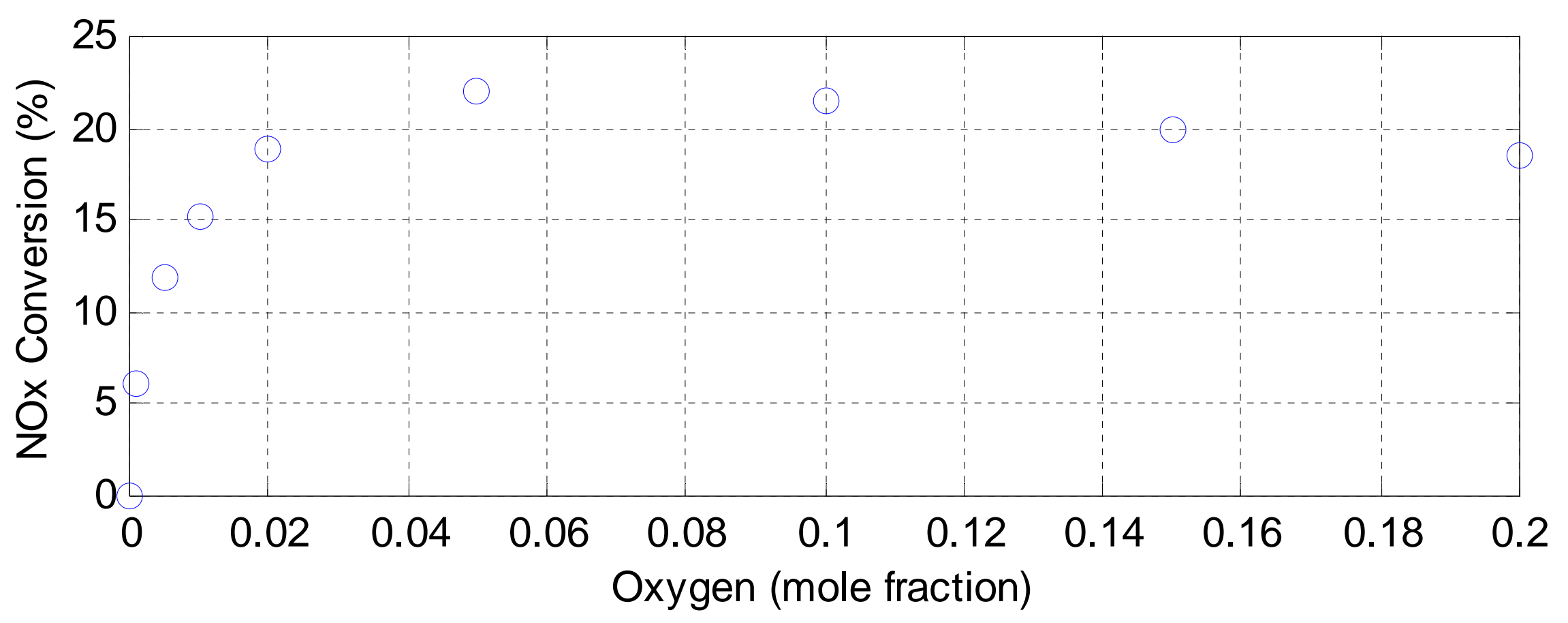




\section{SUMMARY OF LEAN NOX TECHNOLOGY}

- Can use on-board fuel as reductant.

-With special reductants e.g., Fisher Tropsch (FT) and Hexadecane (C16), has higher NOx reduction efficiencies.

-The temperature window for precious metal lean NOx catalyst is a good fit for light duty applications.

-Precious metal catalyst is only slightly inhibited by $\mathrm{H}_{2} \mathrm{O}$.

-Simple injection strategy. 


\section{SUMMARY OF LEAN NOX TECHNOLOGY}

\section{Issues:}

-Platinum catalysts generate large amounts of $\mathrm{N}_{2} \mathrm{O}$ (currently not regulated, green house gas).

-The temperature window of the catalyst is narrow leading to limitations in cycle efficiency.

- Pt catalyst have increased $\mathrm{SO}_{2}$ activity leading to increased sulfate particulate. 